\title{
Study on the Influence of Homophones in Modern Chinese on Communication
}

\author{
Li Zhang \\ Xi’an Fanyi University, Xi'an, Shaanxi, 710105
}

Keywords: Homophones in Modern Chinese, Communication, Influence

\begin{abstract}
The existence of a large number of homophones in modern Chinese is bound to exert some influence on the use of Chinese. Of course, the impact is twofold, with both negative and positive effects. This is a linguistic fact. As Huai Qing pointed out in Modern Chinese Vocabulary, on the one hand, he pointed out: "The existence of polysemy and homophone is a manifestation of simple economy of language symbols, which makes it easy to grasp and use. Some people talk about polysemy and homonyms to the language Confusion caused by them, they did not think that if the language was to completely eliminate the polysemy and the homophone, the disorder caused by it would not be known to be many times larger than it is now. Therefore, to make the linguistic symbols simple and economical and easy to grasp and use is the polysemous and homophone an important positive effect on language ". On the other hand, he also pointed out: "Due to the abundance of homophone (including homophones, homophones and morphemes) in Mandarin, it increases the difficulty of identification. This is one of the important reasons why writing is easy to type."
\end{abstract}

\section{Introduction}

The use of homophonic pun, to express "the word here, intended to be." Meaning. Make the language look vivid, subtle and thought-provoking. Ancient poetry often use this technique to express, such as: "Spring silkworms should not be old, day and night often wire. When Xi Wei Xuqiong do, touching its own time." (Southern Yuefu "for silk") here "silk" Thinking of "thinking." Another example is the "Yangliuqing Qingjiang River level, sang Lang Lang singing. East sunrise on the west side of the rain, the road is merciless but affectionate." (Liu Yuxi "Zhuzhici") Here the "love" Shuangguan sunny "feeling", Expressed the complex love of the first girl complex subtle psychology.

In modern times, Comrade Mao Zedong's "Die Lianhua • Youxian (A Li Shuyi)" starts with "I am despised by Yang Jun and Liu." This is the form of homophonic pun of Yang Kaihui and Liu Zhixun's two martyrs Unforgettable reminiscence of love. In addition, some literary works often use homophones constitute a homonym, hidden taboo expression of the author's love and hate and deep complex thoughts. Such as "Dream of the Red Chamber" in the Jia Yucun, Zhi Yanzhai commentary will be considered "false language village" homonym, Zhen Shi hidden "truth hidden" homonym, incense lotus is "phase mercy" homonym.

In today's market economy, the role of advertisements is more and more important. It is also becoming more and more common to use the homophonic sounds of idioms to advertise. We can always see or hear:

Juice is coming - the name of a canteen

Food Beauty - CCTV's name for a food program

Eat new food is different, eat whole food beauty - Shanghai First Food Company's ad

Perplexity - Someone's assessment of the current stock market

Love too much - a coffee bar name

Investment vote is Road - a shooting playground name

Bathing - water heater ad

Cough not delay - cough medicine ad

Happy riding - motorcycle ad

Silent mosquito - mosquito ad 
Step by step - shoes ad

Clothing pull off - clothing store name

When we read or hear such advertisements, the first impression is that everything is refreshing and fun. Advertising can use idioms to form a homonym. Because people are familiar with these idioms, they are very easy to remember and spread, resulting in a good economy effect. But on the other hand, the abuse of idioms is not conducive to the standardization of language, it seems to be less useful.

1.2 special context to achieve homophonic humorous, ironic effect

Whether in conversation or in writing or painting, humor and irony can be achieved by using homonyms. Such as Lao She "broken soul gun" in the sand dragon encounter apprentice fight or dedication to discuss a tricks, sometimes joking sloppy past: "teach what? Take away the water!" And "Third Sister Liu", "Surnamed Tao not see peach results, surnamed Li not see Li flowering, surnamed Luo gongs and drums, three fools where come?" Third Sister Liu on "Tao, Li, Luo," three surname and "peach, Lee, Gong" Harmony cleverly surnamed Conjunction, refers to the object of borrowing, to the landowners old money as an accomplice three scholar conducted a spicy taunt. In some cases, homonyms are also used to express the meaning of covert associations. For example, in the old society, some people used "2345" and "6879" to form the riddle of parataxis, with "one less than ten" or "missing" Eat less clothes, "the answer, exposing the social reality of the people live in abyss.

\section{Negative impact}

In modern Chinese, homonyms are commonly used and misused. It is more or less common in all texts that people have access to, from the composition of primary and secondary school students, to the dissertations of teachers and scholars, to the articles of newspapers and magazines, and then to Subtitles to film and television, wherever we can see, can think of places there may be homonyms misuse. However, due to the limited energy and ability of the human being, we can not take all the textual materials for analysis and examination. We can only cite a few concrete examples to illustrate the phenomenon of homonyms misuse in modern Chinese. We try to derive us of the problem, and investigate this research.

(1) This letter was written on the evening of January 9, 1969 but was not sent and was detained by an unlawful individual. "Seizure" and "withhold" homophones, but the meaning and usage are different. The former is detained, the meaning of detention, the object is mostly guilty of the others; the latter is not allowed to handle the meaning of detention, the object is mostly letters, materials and so on. In the case of "seizure" is obviously misuse, it should be "withheld" talent.

(2) In short, Grandpa has this threshold as Zhang's boundary, no matter what the threshold outside the threshold change, but within the threshold is Zhang dominated the world. (Liu Xuezhi "threshold") things in one form or content into another, that is "change", such as "change position" / "change of technique" and so on; "change" refers to the unpredictable and irregular change, often used to describe changes in the natural landscape or form. Irregular changes in the situation, it is difficult to "change", was a "change" misuse.

(3) telephone line is the Internet "must goods." "Necessity" refers to indispensable articles of life. According to the statement, we should not make mistakes, but "must" and "necessary", "need" and "need", and the existence of these homophones interferes with people's choices. In this case "must" is "necessary" misuse.

Let us look at a more typical example, "points" and "share." The following is an example of the misuse of "sub" and "part" we found in an Ru Pan and Zhao Yuling's "Misunderstanding of Common Words" (Tide Publishing House, Beijing, July 2001) The word is the selected word, the latter word is the misuse of the word).

Security points / security points. I heard white butterfly restless childhood, more fantasy, a world can not tolerate her, the world can not accept her.

Generation / seniority. When asked when she was going to hold a solo exhibition in Beijing? She laughed: "China, ... profound ... my senior ... there will be that day" and so on. 
This part / this. This tall man, black and yellow skin, at first glance looks like a honest part of the farmers.

Extra / extra. Silver Dragon Restaurant crispy roasted suckling pigs, but extra-lovable ......

Blessing / blessing Now we are in Beijing, who can live bright and spacious with "double gas" of the building, then the blessing is not superficial.

Over / over Qiu Xiao think he is doing a bit too much public places.

Weight / weight. You can feel the weight of these four words, you also feel a responsibility.

Nutrient / Nutrient Long-term use of the brain, so that increased blood viscosity of the brain, nutrient supply is not on the brain cells decreased vitality, it is easy to form brain fatigue.

Only in this book we have found a lot of examples of misuse, which can also be seen misuse of the problem is still more serious. In the above example, "minute" is easy to mix with "copy" when it is heard, and often misused as "copy." There is a clear difference between the meanings of "points" and "parts" in reading aloud and generally can not be used universally.

From the large number of examples cited above, we can easily see that people use homophones, words in the process, due to various reasons, there will often be misuse, mixed phenomenon. This will inevitably bring some problems and difficulties to our linguistic research and linguistic norms. Homonyms misuse of what is the reason, there is no regularity or tendency, in the daily communication process to take what kind of countermeasures to reduce misuse, this series of issues require our serious consideration. This article focuses on the countermeasures to reduce the negative impact, expecting to find some findings and opening up new ideas for linguistic research.

First of all, since homophones have the same pronunciation, the semantic expression is often unknown. In a communicative environment, people have some troubles. For example, when it comes to "we lack", it is difficult to distinguish between "financial resources" and " force". Like the same part of speech, but also belong to the same scope of application, often appear in the same language environment, sounds likely to cause confusion of meaning, affecting the transmission and exchange of information.

Secondly, the large number of homophones also makes many people appear in the writing of Chinese characters. For example, "Oh sighs" written as "lamenting sighs", "do nothing" as "a worry show", "endless stream" written as "continuous flow", which naturally and the writer's understanding of the word semantics is unknown, and this understanding is unknown, can not but say that a large part is caused by homophones. Great confusion in written communication.

Finally, from the perspective of information theory, the appearance of homophones will inevitably reduce the amount of information carried by the word. In most cases, the homonym can be ambiguous by the context, but when the homophones are more than a certain degree, the context sometimes does not It is too easy to rule out these ambiguities because the amount of information provided by the word is inversely proportional to the probability of the word occurring in a given context. With the increase of homophones, the probability of the same sound form appearing in the same context increases correspondingly, and the probability of appearance increases, which leads to the "dilution effect" of information, which leads to the decrease of the amount of information of words, which is unfavorable Information Communication in Language Communication. From the previous statistics, the homophones in monosyllabic words are prominent. A lot of monosyllabic words share the same phonetic form, with an average of 7.98 different monosyllable words per syllable, and the highest one has 93 homophones, making the voice The role of the form of the relative weakening.

From the perspective of semantics, the differentiation of lexical meaning is one of the main reasons for homophone generation, which also greatly increases the number of homophones. Homophones increase, and the requirements for context in the actual communication of language are even higher, making the use of language less clear and accurate. Because of this, so in the communication, sometimes cause confusion in meaning, affect the expression of ideological content, and even cause misunderstanding is normal. For example, "she's a bit arrogant / squeamish" or "midterm / midterm exam", without explanation, it is difficult to let the listener understand what it means. 


\section{References}

[1] Hu Yushu. Modern Chinese [M]. Xi'an: Shaanxi People's Education Press, 1998.6

[2] Cao Wei. Modern Chinese Vocabulary Study [M]. Beijing: Peking University Press, 2004.3

[3] Fu Huai Qing. Modern Chinese vocabulary [M]. Beijing. Peking University Press, 1985

[4] Gengyu Ge. Modern Chinese Vocabulary [M]. Jinan: Shandong People's Publishing House, 2001

[5] Qi Shanghai Yang. Chinese General [M]. Beijing. China Radio and Television University Press, 2003.12

[6] Shao Jingmin. Modern Chinese General [M]. Shanghai Education Press, 2001.6

[7] Yu Yunxia. Homophone analysis [M]. Beijing: Beijing Language and Culture Institute Press, 1992

[8] Zhang Zhiyi. Vocabulary Linguistics [M]. Beijing: Commercial Press, 2001 